\title{
Monitoring of a Bridge with Integral Abutment
}

Martin Nilsson, MSc

PhD student

Luleå University of

Technology

Milan Veljkovic, PhD,

Associate Prof.

Luleå University of

technology

\author{
Wylliam Husson, MSc \\ PhD student \\ Luleå University of \\ Tchnology
}

\author{
Peter Collin, PhD, \\ Professor \\ Ramböll and Luleå \\ University of technology
}

\author{
Hans Petursson, Tech. Lic. \\ Ramböll and PhD student at \\ Luleå University of \\ technology
}

\section{Summary}

Preliminary results obtained from short term test-loading are used to illustrate possibilities of FEM used to calibrate complex interaction characteristics between a pile and soil in a bridge with integral abutments. The measurements are obtained during the winter season on the bridge over Ledån, Northern Sweden. The bridge is built in 2006 and used for long term monitoring within the international project supported by RFCS. The main objective of the on-going research project is to proposed recommendations for rational analysis and design of bridges with integral abutments.

Keywords:bridges with integral abutments, steel pile, bridge monitoring, FEA, soil-pile interaction.

\section{Introduction}

Integral abutment bridges are bridges without any expansion joints, and their largest benefits are the lower construction and maintenance costs. The abutments are generally supported on a single row of steel piles to provide the required flexibility for accommodating the longitudinal bridge movements due to daily and seasonal temperature variations. Such movements impose cyclic lateral displacements on the abutments, backfill and the steel piles. The magnitude of these cyclic displacements is a function of the level of temperature variation, type of the superstructure material and the length of the bridge.

The first bridges with integral abutments have been built in 1960's in USA and in recent years this type of bridges gain popularity in Europe, primarily in UK and Scandinavian countries. The maximum span width as well as a total bridge length has been increasing through the years. The length of the longest concrete bridge is $358 \mathrm{~m}$ Tennessee State Route 50 over Happy Hollow Creek. The longest steel girder integral bridge has span of $318 \mathrm{~m}$ in Colorado state [1]. It is obvious that countries, such as USA, with design requirements more open towards new technologies encouraging implementation innovative solutions even if they not thoroughly examined. Although nationally accepted design specifications for integral bridges do not exist, each highway department is allowed to make decisions depending on their own expertises.

In Sweden, the maximum and minimum characteristic temperatures, which statistically occur once in 50 years, are varying between $30^{\circ} \mathrm{C}$ and $38^{\circ} \mathrm{C}$ respectively $-20^{\circ} \mathrm{C}$ and $-48^{\circ} \mathrm{C}$. This rather large temperature differences decreases the upper length limit, compared to the USA. Some states in the USA allow plastic strains to be developed in the steel piles used below the abutment back walls.

Just a few bridges with integral abutments were built in Sweden in 1980's. The main obstacle for wider acceptance of this type of bridges is a lack of recommendations for rational analysis and design. According to Swedish code for bridges BRO 2004

[2] no plastic strains are allowed at serviceability limit state even if the critical section is at the top of a pile. Such high strain may occur due to seasonal temperature variation, a couple of time a year, and are limited at the very narrow region. These effects may cause low-cyclic fatigue which will be 
thoroughly examined in an on-going RFCS project, INTAB- Economic and Durable Design of Composite Bridges with Integral Abutments, running in period 2005-2008.

The first investigation focusing on development of rational design for steel piles was initiated at LTU in late nineties and results are published in [3], and recently in [4] and [[5].

The major complexity of the integral bridges is actually in soil-structure interaction that requires the coordinated attention of both structural/bridge and geotechnical engineers. A need for a multidisciplinary team in design practice is clearly identified and recommended for finding a most economical solution.

The most recent results presented in [6] are using in the on-going project to achieve a rational methodology which is required to determine the maximum length limits for integral bridges.

\subsection{Bridge over Leduån River}

In the end of 2005, the Swedish National Road Administration ordered an integral bridge as a part of a research and development program. The bridge would be continuously monitored by Luleå University of Technology. The researchers were involved in an early stage in order to make sure that the design of the bridge and the construction enabled continuously field measurements.

The bridge was designed as a single span composite bridge with a span length of $40 \mathrm{~m}$ and a width of $5 \mathrm{~m}$. Six vertical end bearing steel pipe piles, nominal dimensions $\varnothing 170 \times 10$, are supporting each abutment. The soil surrounding is mainly silty fine sand to fine sandy silt. The abutments are designed with a shelf at the bottom, Fig. 1. This makes it possible for the piles to pass rather sheltered through the crushed stone used at erosion protection. The free distance between the piles and the concrete back wall is nominally $80 \mathrm{~mm}$. The two meters of the piles below the bottom of the abutment were protected by a sheltering steel pipe, Ø600, filled with loose sand. The piles were also wrapped in with Styrofoam sheets where they passed through the sheltering pipes.

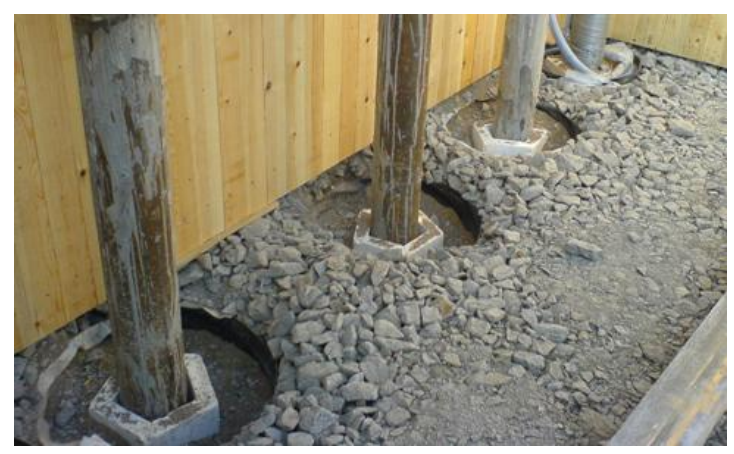

Fig. 1 Piles are wrapped in with Styrofoam

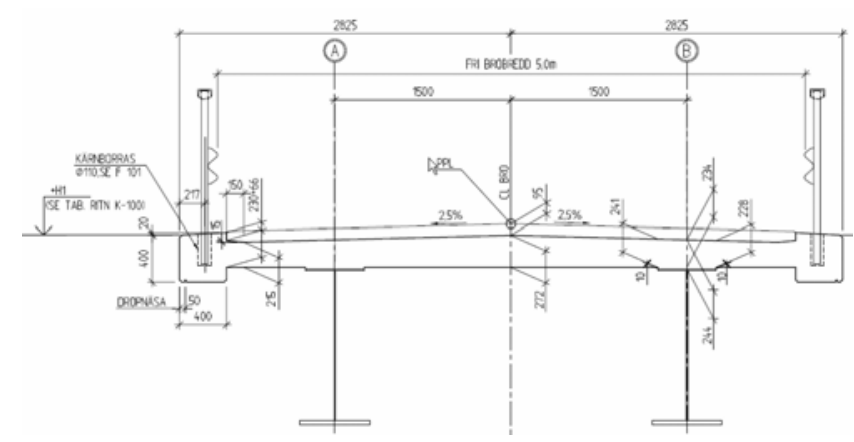

Fig. 2 Cross section of the bridge

A conventional concrete bridge had also been designed as an alternative to the integral abutment bridge. That design demanded an internal support in the river, including a more complicated foundation work. The cost estimation for the integral abutment bridge showed that it in this case was economically superior compared to the conventional design. This cost estimation was made without taking the maintenance costs into account, which would have made the integral abutment bridge even more competitive.

The construction procedure from the foundation work to the finishing of the superstructure, can be described as following 
- The area where the piles shall be driven are excavated down to about $2 \mathrm{~m}$ below the bottom of the abutment.

- The piles are driven in accordance with the construction drawings. The tolerances in the longitudinal direction are set as $\pm 100 \mathrm{~mm}$. The piles have $12 \mathrm{~m}$ sections and are but welded in end-to-end connections.

- The pile inclination and straightness are measured, and the results are forwarded to the bridge designer.

- $\quad$ Sheltering piles, Ø600, are placed around the piles with the piles in the centre of the pipe. Piles are wrapped in with Styrofoam sheets and loose sand is filled in the pipe.

- $\quad$ The foundation work is then made up to the level of abutment bottoms.

- The lower part of the abutment back walls is cast at the same time as the wing walls.

- The supports below the wing walls are removed, resulting in a pile moment in the opposite direction of the moments acting on the finished structure. The moment from the wing walls can bee seen as a prestressing of the pile.

- $\quad$ Steel girders are mounted on temporary steel bearings.

- $\quad$ Bridge deck and the upper part of the abutment back walls are cast in an ordinary way. The concrete in the upper part of the back wall shall be cast last.

- $\quad$ Pavement and rails are placed on the bridge.

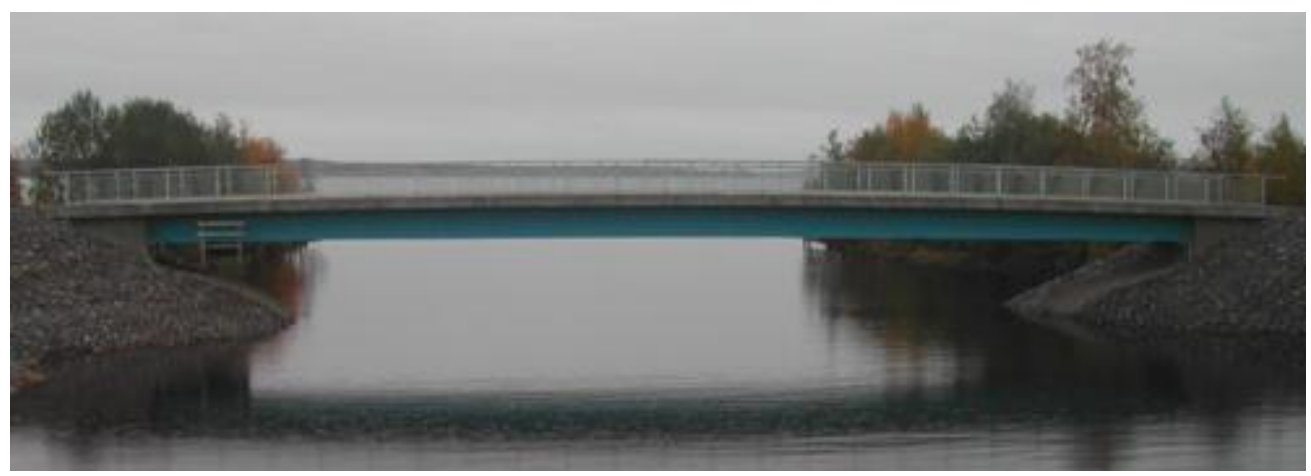

Fig. 3 The Leduån Bridge.

\section{The on-going research at LTU}

The main research activity is caring out within a European R\&D project, INTAB-Economic and Durable Design of Composite Bridges with Integral Abutments, financially supported by RFCS (Research Fund for Coal and Steel) and SBUF (Development Fund of the Swedish Construction Industry). There are two major project objectives, a concept saving investment and maintenance costs. The project includes international comparisons, theoretical studies, in-situ and laboratory testing of bridges and the preparing for guidelines for design of such bridges. The major objectives of the project are the development of cost effective, environmental friendly and sustainable bridge structures. The project is focused on composite bridges and the improvement of their durability in order to make them even more competitive. 
The partners involved in the project are:

- RWTH Aachen, Germany

- University of Liège, Belgium

- ProfilARBED, Luxembourg

- Ramböll Sverige AB, Sweden

- Luleå University of Technology, Sweden

- Schmitt Stumpf Fruehauf und Partner, Germany as an associated partner

\subsection{Monitoring program}

To gain knowledge about the overall behaviour of the bridge a total of 34 measuments will be constantly recorded and stored in period of at least 15 months, starting from autumn of 2006. Strain-gauges were welded to the bridge girder and to the pile, as shown in Fig. 4.

Strains in the piles are measuring at five different levels with the two strain-gauges at each level. The strain-gauges position is such that the maximum strains are measuring. At the upper four levels, called N1-N4 and S1-S4, for the north and south side of the bridge respectively, the stored signal consists of the difference between two strain-gauges. Signals obtained from both pairs of straingauges; at the fifth level, N5 and S5, are storing separately. An estimation of the axial force in the pile is possible from the measurements at the fifth level.

The movement of the abutment walls is measuring with level indicators, two at each side of the bridge. Their position is indicated by numbers 6 and 7 in Fig. 4. The level indicators were placed in a vertical plane along the centre line of the bridge at a distance of $1.5 \mathrm{~m}$. With known geometry of the abutment, rotation and displacement of the pile top is estimated from these measurments.

Two strain-gages were welded at the steel girder, close to the south abutment, to get an indication of the moment constrained obtained at the bridge end. Strain-gages were placed at the upper and lower flange, pos. 8 and 9 respectively.

Strain-gages were also welded to the upper and lower flanges at the midspan of the bridge, pos. 10 and 11. for the estimation of the overall bridge behaviour.

Effects of temperature seasonal variation is very important effect that influence strains at the top of the pile. Therefore, the air temperature as well as temperatures at three positions of the bridge; on the upper flange, on the lower flange, in the concrete, position 10, 11 and 12 respectively; were stored. 


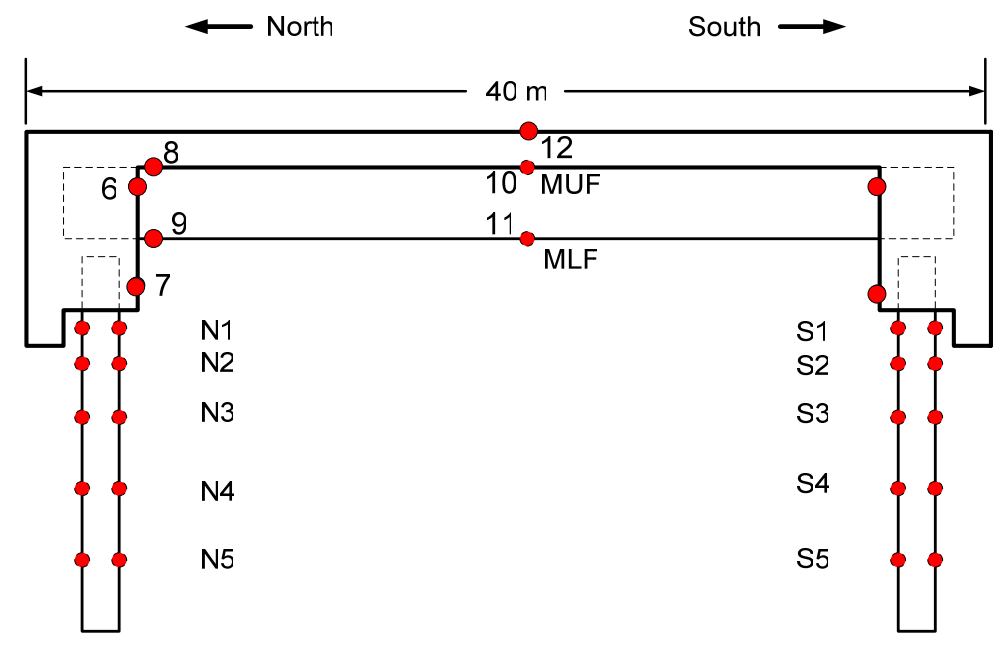

Fig. 4 Position of long term monitoring gauges at the Leduån bridge

\subsection{Evaluation of the short term test-loading}

A lorry which has a mass of $24,4 \mathrm{t}$ and has passed over the bridge at an average speed of $1 \mathrm{~m} / \mathrm{sec}$ was used to obtain effects referred in the text as the short term test-loading. The similar loading will be performed every three months. Possible seasonal difference of the soil condition and its material properties will be estimated from these measurements. The first short term test-loading was performed in January 2007. The air temperature at the bridge location was as low as $-20^{\circ} \mathrm{C}$ in a period of a couple of days priori the measurements.

The pile top is embedded in the abutment wall. Therefore, the lateral displacement and the rotation at the pile top are obtained from the measured rigid body movement of the abutment; pos. 6 and 7.

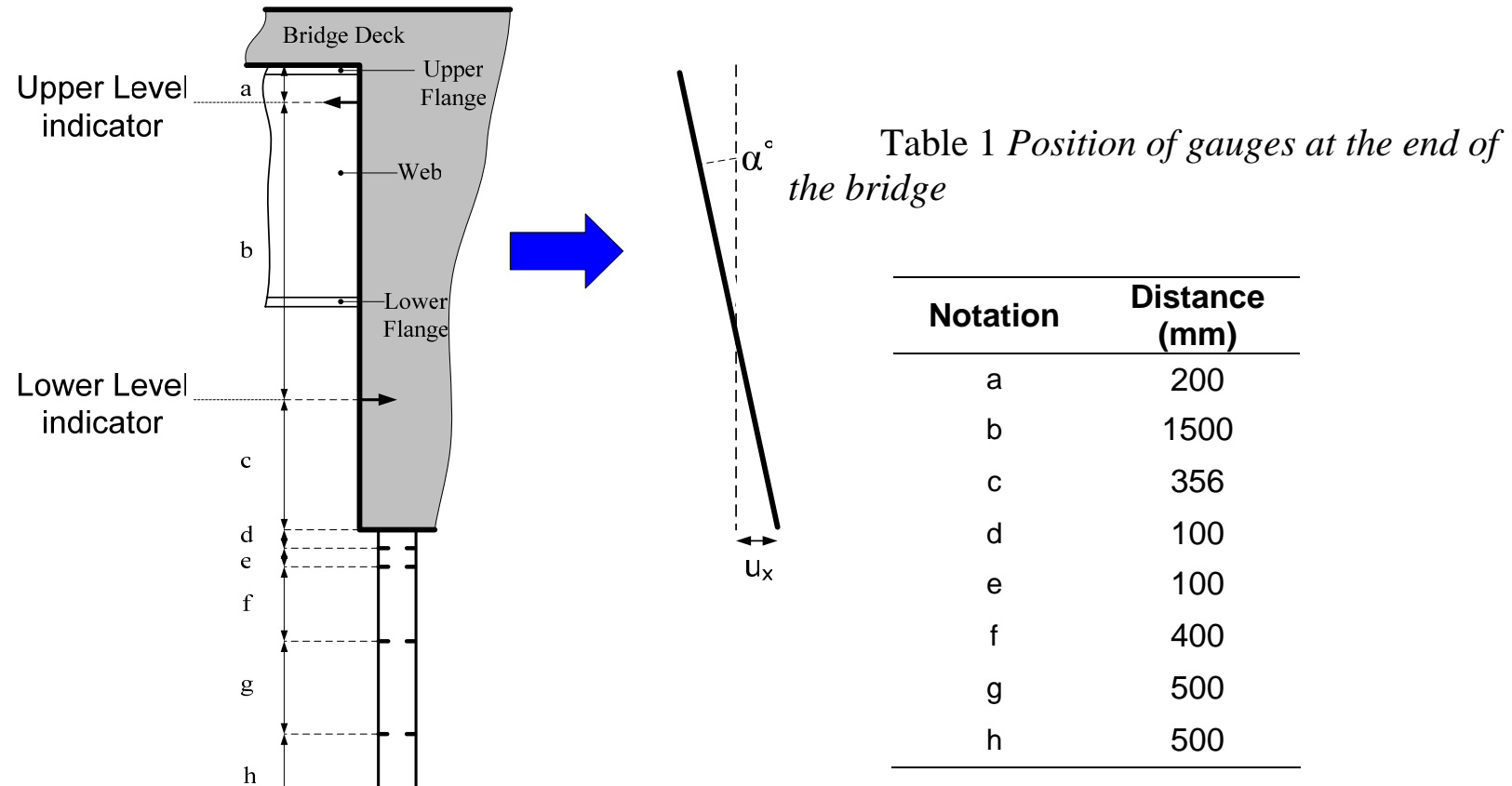

Fig. 5 Measurement of the abutment rotation and its effect on the pile 


\subsubsection{Measurements at the piles}

Results from the measurements obtained from one pile at the north and one pile from the south abutments shows similar pattern, after the lorry has passed over the bridge small strains, at the level of 10 micro strains, remains in the pile indicating an axial compressive force and a small curvature. These preliminary results indicate a good quality of measurements and expected behaviour of the pile. Interpretation of the measurements is on-going work and a preliminary analysis of the soil characteristic is given below.

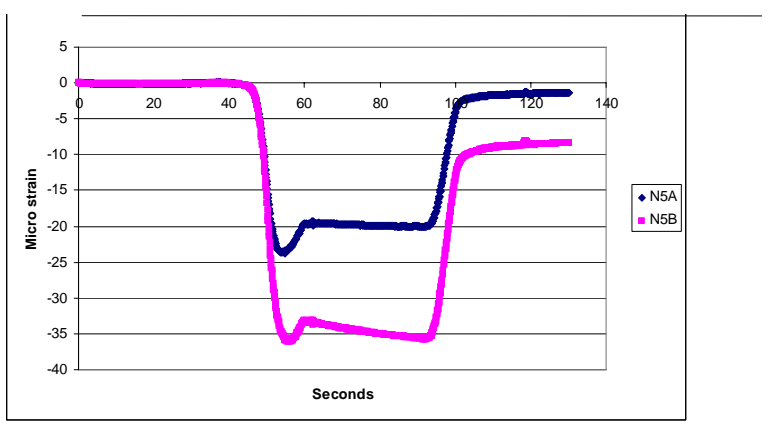

Fig. 6 Measurements at the north pile, N5

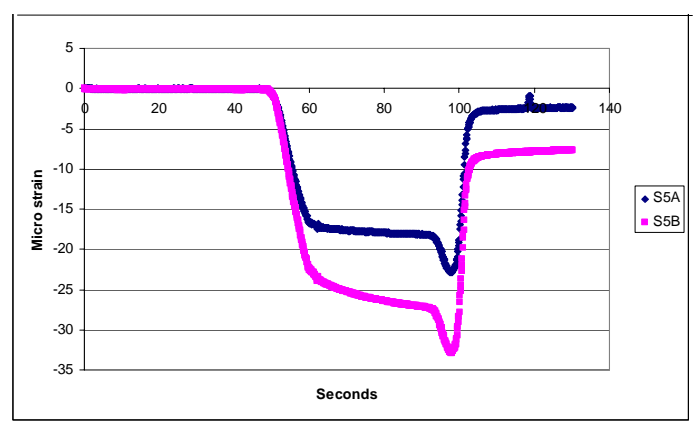

Fig. 7 Measurements at the south pile, S5

\subsubsection{FE model of the pile}

FEA is used to interpret behaviour of the measurements. One of the parameters that is rather difficult to measure is the properties of the soil. This issue is indirectly estimated calibrating results of a rather simple 2D FE model with the measured data. The pile is modelled by beam elements, using elasto-plastic hardening material and von Misses yield criterion. The soil influence is modelled by elastic two node spring elements. The spring elements connect the pile nodes to fixed reference points and provide only horizontal support. Totally 69 spring-elements were used, more tightly distributed at the top of the pile, where changes of slopes occur. The distances between the springs are in a range between $0.05 \mathrm{~m}$ to $0.15 \mathrm{~m}$. Every spring has a particular property allocated to produce a reaction force equivalent to a soil layer centred at the point of connection.

Recommendations from the Swedish bridge code [2] are used in the design for the definition of the spring stiffness.

The spring stiffness, $\mathrm{k}$, is then:

$$
\begin{aligned}
k & =k_{k} \cdot A_{\text {Spring }} \\
& =k_{k} \cdot d . s
\end{aligned}
$$

Where $A_{\text {spring }}$ is the projected pile-soil contact area related to one spring, $d$ is the pile outer diameter, and $\mathrm{s}$ the distance between two springs, $\mathrm{k}_{\mathrm{k}}\left[\mathrm{MN} / \mathrm{m}^{3}\right]$ is the subgrade reaction modulus at the depth $\mathrm{z}$. For friction type soil no difference is made between short term and long term stiffness and the subgrade reaction modulus is given by:

$$
k_{k}=\frac{n_{h} \cdot z}{d}
$$

The constant of subgrade reaction modulus, $\mathrm{n}_{h}\left[\mathrm{MN} / \mathrm{m}^{3}\right]$, can be found in tables. According to geotechnical analysis, the soil surrounding the piles is sand with a very low consistency. Thus $n_{h}$ is taken as:

- $2,5 \mathrm{MN} / \mathrm{m}^{3}$ over the ground water level

- $1,5 \mathrm{MN} / \mathrm{m}^{3}$ under the ground water level 
In the considered soil model, the soil stiffness increases linearly with the depth until a maximum value of the product $k_{k}$. $d$ is reached and it then remains constant.

For sand with a very low consistency, these limits are, $\left(k_{k} \cdot d\right)_{\max }$ :

- $4,28 \mathrm{MN} / \mathrm{m}^{2}$ over the ground water level

- $2,57 \mathrm{MN} / \mathrm{m}^{2}$ under the ground water level

In a process of calibration of FE model, the characteristic soil properties were considered.

The ground water level is supposed to be at the top of the pile.

The depth at which the stiffness stops increasing and remains constant can be derived from $\mathrm{k}_{\mathrm{k}} \cdot \mathrm{d}$ and $\mathrm{n}_{\mathrm{h}}$ :

$$
z_{c}=\frac{k_{k} \cdot d}{n_{h}}=4,28 / 2,5=1,71 m
$$

and the corresponding stiffness is:

$$
k_{c}=\left(k_{k} \cdot d\right)_{\max } \cdot s
$$

Table 2 Properties of the soil along the pile, according to BRO2004 [2]

\begin{tabular}{|l|l|l|}
\hline \multirow{2}{*}{$\begin{array}{l}\text { Below } \\
\text { ground water }\end{array}$} & $\begin{array}{l}\text { Linear increase } \\
0,00-1,71 \mathrm{~m}\end{array}$ & $\mathrm{n}_{\mathrm{hd}}=1,5 \mathrm{MN} / \mathrm{m}^{3}$ \\
\cline { 2 - 3 } & $\begin{array}{l}\text { Constant } \\
\text { stiffness } \\
1,71-6,00 \mathrm{~m}\end{array}$ & $\mathrm{k}_{\mathrm{k}} \cdot \mathrm{d}=2,57 \mathrm{MN} / \mathrm{m}^{2}$ \\
\hline
\end{tabular}

Results of FE calculations with soil properties used for design according to[2] gives lower strains than those measured on site. FEA indicates a higher curvature that must be due to a stronger lateral support of the pile from the surrounding soil. It is important to notice that the short term testloading was performed in winter as temperatures were very close to the minimal and the soil was probably frozen. It is know from [6] that the soil stiffness may be increased approximately by a factor 30 compared to unfrozen soil below ground water level.

For the northern pile the results of FEA fit the measurements best for a soil with a constant stiffness 20 to 30 times higher than that of the unfrozen soil below the ground water down to a depth of $2 \mathrm{~m}$. Below that level the characteristic soil of the norm is used. The behaviour of the southern pile is different. The soil parameters appears to be higher only by factor 5 to 10 .

The work on calibration of soil-pile interaction parameters is continuing using a more complex model in 3D where the solid elements will be used to model soil-pile interaction at the ultimate limit state. Results of the calibration will be used in a complete bridge model. The results of the monitoring collected from measuring places at the bridge girders will be compared to the complete bridge model results. 

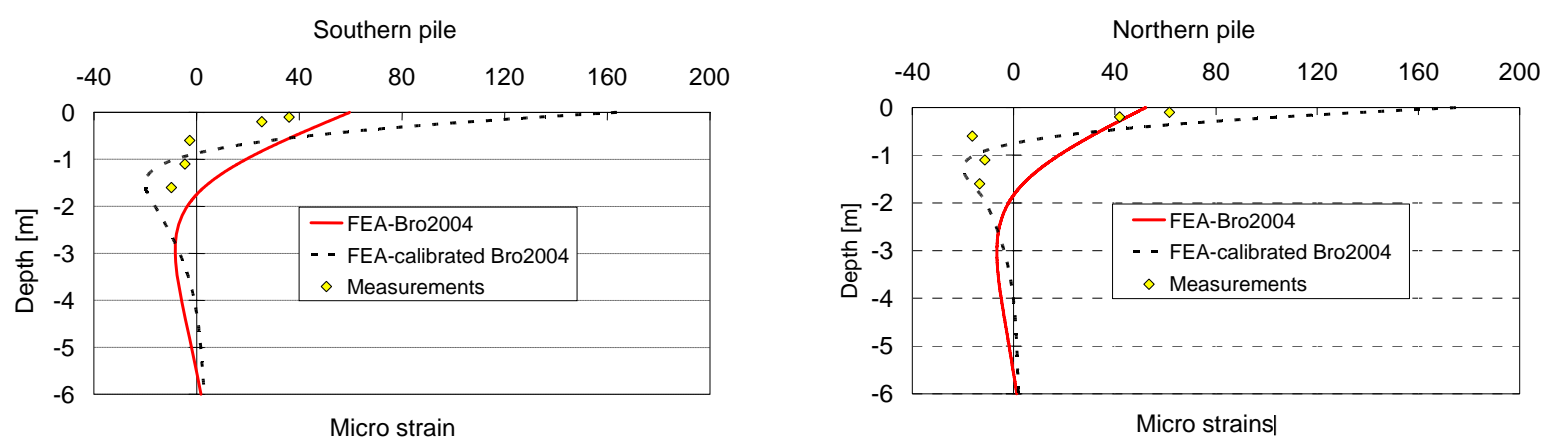

Fig. 8 Calibration of the soil parameters by FEA

\section{Conclusions}

The preliminary results obtained from the monitoring of the Leduån bridge indicate that rather simple FE model, suitable for design practice, may be used to calibrate unknown parameters of the soil under the traffic load.

Results from the measurements, obtained in January 2007, indicates stronger stiffness of the soil in a range between 10 to 20 times more compare to stiffness of an unfrozen soil.

The strains from the bending moment in the piles caused by the traffic load of the 24t lorry are very low, where the maximum strain measured was about 60 micro strains.

\section{Acknowledgements}

Financial support obtained from the RFCS, contact number and from SBUF is gratefully acknowledged. The work on the instrumentation of the bridge was carried out by an excellent team consisting of Georg Danielsson and Lrs Åström, both from TestLab at LTU. Authors are gratefull to other partners in INTAB project for very friendly atmosphere and fruitful discussions on the projects meetings.

\section{References}

[1] Hassiotis, A.,S., and Roman, E.K. Survey of current issues on the use of integral abutment bridges, Bridge Structures, Vol. 1, No. 2, June 2005, 81 - 101

[2] Swedish code for bridges, BRO 2004, Väggverket, The Swedish National Road Administration, in Swedish, http://www.vv.se/templates/page3_7900.aspx , the last time visited in March 2007

[3] Pétursson Hans, Broar med integrerade landfästen, Licentiatuppsats (2000) ISSN: 1402-1757

[4] Tlustochowicz, G., Optimized design of Integral Abutments for a Three Span Composite Bridge, Master Thesis, 2005:248 CIV, Luleå University of Technology, http://epubl.ltu.se/14021617/2005/248/LTU-EX-05248-SE.pdf , the last time visited in March 2007

[5] Hällmark R. , Low-cycle fatigue of steel piles in integral abutment bridges, Master Thesis, 2006:291 CIV, Luleå University of Technology, http://epubl.ltu.se/1402-1617/2006/291/LTU-EX06291-SE.pdf , the last time visited in March 2007

[6] Kerokoski, O.; Sillan ja maan yhteistoiminta: liikuntasaumattomiensiltojen laskennallinen tarkastelu. Tampereen teknillinen yliopisto, Maa- ja pohjarakenteiden laitos, tutkimusraportti 70, Tampere. 2006 